\title{
Intimate Partner Violence During the First Year After Childbirth in an Urban Area of Iran: Prevalence and its Predictors
}

\author{
Mahta Amiri $^{\circledR}$, Sakineh Mohammad-Alizadeh-Charandabi ${ }^{{ }^{\star}}{ }^{(\mathbb{D}}$, Mojgan Mirghafourvand $^{2}$, Azizeh $^{\circ}$ \\ Farshbaf-Khalili ${ }^{3}$, Fatemeh Ranjbar ${ }^{4}$
}

\begin{abstract}
Objectives: The present study aimed to assess the prevalence of intimate partner violence (IPV) in the first post $\neg$ partum year and its predictive factors in an urban area of Iran.

Materials and Methods: In this cross-sectional study, 398 women with a healthy infant aged 12 months were examined using revised Conflict Tactics Scale (the CTS2) to determine the prevalence of IPV. The data were collected at the public health centers in Tabriz (from October 2015 to April 2016). The predictors were determined using multivariate binary logistic regression.

Results: More than half of the women (58\%) reported experience of one or more instances of any form of IPV, namely, psychological, physical, sexual, and/or injury and one-third of them reported physical and/or sexual IPV in the first postpartum year. Reported prevalence of each form of IPV were as follows: psychological aggression (54\%), physical assault (21\%), sexual coercion (21\%), and injury (13\%). Predictor factors of overall IPV were: woman aged less than 30 years (adjusted odds ratio 2.0 [95\% CI: 1.3 to 3.3]), unplanned pregnancy (1.6 [1.03 to 2.6]), husband disappointment about their baby's gender [1.9 (1.1 to 3.2)], and inability to fully meet the husband's sexual expectations (1.6 [1.03 to 2.4]).

Conclusions: The IPV during postpartum is very common. Therefore, it is recommended to implement IPV screening programs and effective strategies for IPV prevention in the health care settings for newly delivered women emphasizing on the high risk for the women.

Keywords: IPV, Injury, Women, Postpartum, Predictors, Iran
\end{abstract}

\section{Introduction}

The IPV against women is a global issue, which is known as a public health problem violating human rights for several reasons such as serious adverse effects on women's physical, mental, and reproductive health. According to the World Health Organization (WHO), 30\% of the women experience physical assault or sexual coercion by their sexual partners at least once in their lifetime (1). Moreover, a recent review including 31 studies indicated that the prevalence of intimate partner violence (IPV) in Iran was estimated to be $66 \%$ ranging from $20 \%-93 \%$ in different cities (2).

As it is stated, IPV is a major offense committed by the men against their women during the postpartum period, when the mother should pay full attention to taking care of herself and her baby (1). However, most women are subjected to IPV during this period. According to a review, the frequency of IPV against women has been reported to be higher during the first postpartum year than pregnancy in the majority of studies. Besides, a number of women experience IPV for the first time during the postpartum period (3).

Female IPV victims are at the risk for a number of diseases including depression, chronic mental illnesses, anxiety, posttraumatic stress, suicide, smoking, drug and alcohol abuse, unintended pregnancies, sexually transmitted diseases such as HIV/AIDS, physical injuries resulting in amputation, and even death (4-6). Moreover, negative impact of postpartum IPV on children's health such as increased risk for infant sleep disorders has been previously reported (7). Apart from its devastating physical and psychological effects on women and child health, IPV was believed to cause serious damages to the entire family. Violence was also found to incur enormous cost on countries including the costs of legal services, social support, and health care provision (4).

Further complications can be prevented by identifying predictive factors and taking preventive measures for those who are at risk of IPV. Low family income, low level of women's education, alcohol and drug abuse by women

Received 29 September 2017, Accepted 15 January 2018, Available online 27 January 2018

${ }^{1}$ Students' Research Committee, Faculty of Nursing and Midwifery, Tabriz University of Medical Sciences (TUOMS), Tabriz, Iran. ${ }^{2}$ Social Determinants of Health Research Center, Department of Midwifery, Faculty of Nursing and Midwifery, Tabriz University of Medical Sciences (TUOMS), Tabriz, Iran. ${ }^{3}$ Physical Medicine and Rehabilitation Research Center, Tabriz University of Medical Sciences (TUOMS), Tabriz, Iran. ${ }^{4}$ Research Center of Psychiatry and Behavioral Sciences, Tabriz University of Medical Sciences (TUOMS), Tabriz, Iran.

*Corresponding Author: Sakineh Mohammad-Alizadeh-Charandabi, Fax: +98-41 34752839, Tel: +98 9143136276, Emails: alizades@tbzmed.ac.ir \&mhammadalizadehs@gmail.com 
or their sexual partners (8-10), sexual relationship for less than a year $(9,10)$, young age $(8-10)$, chronic advanced physical disease, chronic psychological disease (11), and raising more than two children under the age of five (8) were mentioned as predictive factors for the IPV.

Several studies have investigated IPV during pregnancy in many countries including Iran $(12,13)$. However, the literature review showed a lack of studies on prevalence of postpartum IPV and its predictive factors in the world; only one study was found on the prevalence of postpartum violence (14) but no study regarding its predictive factors in Iranian context. Accordingly, the present study aimed to investigate the prevalence of overall IPV and its different forms during the first postpartum year and their predictive factors.

\section{Materials and Methods}

In this cross-sectional study, a total of 398 primiparous or multiparous women were examined, that is, those who had given birth 12 to 12 months and 29 days prior the study and also those that had visited the public health centers or posts in Tabriz to vaccinate their one-year-old children. The data were collected from October 2015 to April 2016.

Other inclusion criteria were as follows: 1) women's willingness to participate in the study; 2) having healthy singleton term babies; 3 ) having at least 9 years formal school education (to be able to fill out the questionnaire by themselves); and 4) being permanently married and living with the husband during the past year.

Exclusion criteria were the occurrence of a horrible incident (such as death of a first-degree relative) during the past year, a history of known depression before the pregnancy, and known serious health problems in the woman or her husband.

The sample size of 398 individuals were estimated, given the $53 \%$ prevalence of IPV reported in a similar study, (14), significance level of 0.05 , and $5 \%$ margin of error. This sample size was high enough to achieve other main research objectives with an acceptable confidence level.

Sampling was performed, in all the public health centers (29 health centers and 59 health posts) in Tabriz after obtaining the code of ethics from the Ethics Committee of Tabriz University of Medical Sciences.

According to the census issued in 2016, the capital city of East Azerbaijan province, namely, Tabriz, has a population of 1.77 million and 32000 births per year (15). In Iran, regular childhood immunization including the measles, mumps and rubella (MMR) vaccine is only done at the public health centers. The first dose of MMR vaccine, with higher than $95 \%$ coverage in the country, is injected at 12 months of age, often 1-2 days a week at each center. Therefore, this setting is an appropriate place for easy access to almost all the mothers one year after childbirth, because in almost all the cases, mothers bring their children to the centers for the immunization.
Considering the days when the MMR vaccine was injected at each health center and post, the researcher (first author of the paper) visiting the centers in person selected the participants using random sampling technique. All the eligible women were enrolled at the visiting day. Before enrollment, the aims of the study were explained to the participants, they were assured of confidentiality of their information, and their informed consent were obtained. The participants filled out anonymous questionnaires in a private room before the injection of MMR vaccine. The participants' husbands or one of their relatives usually accompanied them and took care of their children while the women were filling out the questionnaires. In case that no person was accompanied the woman, the researcher helped them with child care so they could carefully complete the questionnaires. For those who could not fill out the questionnaires on the same day due to being in a hurry, another suitable time was arranged for the appointment.

Data collection instruments included socio-demographic and reproductive characteristics questionnaires, and the revised CTS2. The CTS2 is a standardized tool to measure IPV in the past year which is widely used in the studies. This scale consists of 78 questions (39 pair items) measuring the frequency and chronicity of IPV against men and women including five dimensions, namely, negotiation, psychological aggression, physical assault, sexual coercion, and injury. In this study, IPV against women was only measured in four dimensions (i.e., psychological aggression, physical assault, sexual coercion, and injury) employing 33 questions from the CTS2. Psychological aggression dimension consists of 8 questions (minor (3 items) \& severe IPV (5 items)), physical assault dimension includes 12 questions (minor (3 items) \&severe IPV (7 items)), sexual coercion dimension has 7 questions (minor (3 items) \&severe IPV (4 items)), and injury dimension which consists of 6 questions (minor (2 items) \& severe IPV (4 items)). Each question had 8 response options (0-7) measuring the frequency of IPV. Scoring was carried out by considering an average score for each response choice which were as follows: $0=$ never; 1 = once; $2=$ twice; $3=3$ to 5 times; 4 $=6$ to 10 times; $5=11$ to 20 times; $6=$ more than 20 times (the recommended mid-point is 25); and $7=$ not in the past 12 months but occurring before that. To measure the frequency of IPV in the past 12 months, response choices 1-6 in at least one question of any dimensions indicated existence while response choices 0 or 7 in all questions of the dimension were indicators of non-existence of that form of IPV. The lifetime prevalence of IPV was measured through examining the response choice 7 . The IPV chronicity score was calculated by adding the average scores of the questions about the minor and severe IPV of each form. The CTS2 had a high internal consistency with Cronbach a values of 0.79-0.95 recorded for each dimension in its English version (16). The CTS2 had been 
translated into Persian and validated by Ardabily et al and the word "weapon" was omitted from the items because of its incompatibility with Iranian culture. Moreover, the reliability of this scale was confirmed using test-retest method (17).

The SPSS software, version 19 was used for data analysis. Quantitative and qualitative data were described using mean and/or median (standard deviation and/ or percentile 25-75) and frequency (number and percentage), respectively. To determine the unadjusted relationship between socio-demographic and reproductive characteristics and prevalence of any form of IPV, bivariate binary logistic regression was implemented. Then, the independent variables that had $P$ values less than 0.2 in the bivariate tests were placed into the multivariate binary logistic regression model with enter strategy in order to measure each of the independent variable's effects on the prevalence of the IPV and also to calculate the adjusted odds ratio (OR) and 95\% CI. The $P$-value less than 0.05 was considered as statistically significant.

\section{Results}

A total of 504 women were approached of whom 101 were excluded due to unwillingness to participate in the study (40 cases), lack of basic literacy to fill out the questionnaires (50 cases), multiple birth (10 cases), and suffering from mental or nervous system disorders (1 case). Moreover, five incomplete questionnaires were excluded from the analysis. Therefore, totally, 398 completed questionnaires were analyzed.

Women's mean (SD) age was 28 (5\%) and their husbands' age was 33 (3.5\%) years. About half of the couples (52\%) had been married for 5 years or less. Onethird of the women and $28 \%$ of their husbands had less than a high school diploma. A total of $15 \%$ of the women were employed and $57 \%$ of them were primiparous. In $31 \%$ of the cases, the pregnancy was unplanned and in $23 \%$ of them, the husbands were disappointed with the baby's gender. A total of $85 \%$ of the women mentioned that they had not been able to fully meet their husbands' sexual expectations in the first postpartum year. No cases of alcohol or drug addiction were reported among the women. However, only 9 cases of drug addiction were found among the husbands. The prevalence of cigarette or hookah smoking was reported to be $1.3 \%$ and $30 \%$ among the women and their husbands, respectively. More than four-fifth of the women (85\%) were lactating.

More than half of the women (58\%) reported the experience of one or more instances of any form of IPV (i.e., psychological, physical, sexual, and/or injury) and one-third of them (33\%) reported physical and/or sexual IPV in the first postpartum year. Reported prevalence of each form of IPV in the first postpartum year were: psychological aggression (54\%), physical assault (21\%), sexual coercion $(21 \%)$, and injury (13\%). In addition, lifetime prevalence of overall and each form of IPV were only slightly higher than that in the past 12 months and $59 \%$ of the women reported experience of one or more instances of any form of IPV in their lifetime. Among women with positive experience of IPV, mean times of different forms of IPV in the past 12 months ranged between 8 to 16 and their median ranged between 2 to 7 (Tables 1, 2 and Figure 1).

Bivariate regression showed that there was no statistically significant relationship between the experience of IPV and variables of husband age, woman educational level, woman employment, woman obesity, parity, breastfeeding status, and husband cigarette or hookah smoking. The results demonstrated significantly higher experience of IPV among woman aged less than 30, those with the length of marriage of 5 years or less, husband educational level of 12 years or less, insufficiency of family income for expenses, unplanned pregnancy, husband disappointment about their baby's gender, not fully meeting husband sexual expectations in the first postpartum year (Table 3).

The variables which had significant relationship with experience of IPV as well as woman educational level

Table 1. Prevalence of IPV as Reported by the Women at 12th Month After Delivery $(\mathrm{N}=398)$

\begin{tabular}{lcc}
\hline Form of IPV & $\begin{array}{c}\text { During the First Year } \\
\text { Postpartum }\end{array}$ & Lifetime \\
\hline Psychological aggression & $216(54.3)$ & $236(59.3)$ \\
Physical assault & $82(20.6)$ & $93(23.4)$ \\
Sexual coercion & $84(21.1)$ & $99(25.0)$ \\
Injury & $52(13.1)$ & $62(15.6)$ \\
Physical and/or sexual & $131(33.0)$ & $149(37.4)$ \\
Overall* & $229(57.5)$ & $236(59.3)$ \\
\hline
\end{tabular}

IPV: intimate partner violence.

Note. Data indicate the number (\%).

* Experience of one or more instances of any form of violence (psychological, physical, sexual, or injury).

Table 2. Prevalence and Chronicity of Postpartum IPV Used as Reported by the Women at $12^{\text {th }}$ Month After Delivery

\begin{tabular}{lccc}
\hline \multirow{2}{*}{ Forms of IPV } & Prevalence (\%) & $\begin{array}{r}\text { Chronicity Among Those With } \\
\text { Experience of Violence }\end{array}$ \\
\cline { 2 - 4 } & $\mathbf{N}=398$ & Mean (SD) & Median (p25-p75) \\
\hline $\begin{array}{l}\text { Psychological aggression } \\
\text { Minor }\end{array}$ & $192(48.2)$ & $11.5(14.3)$ & $5(2-16)$ \\
Sever & $145(36.4)$ & $10.7(13.1)$ & $5(2-15)$ \\
Physical assault & & & \\
Minor & $77(19.3)$ & $10(17.5)$ & $2(1-8)$ \\
Sever & $40(10.1)$ & $15.8(29.7)$ & $4.5(1-13.7)$ \\
Sexual coercion & & & $4(2-12)$ \\
Minor & $78(19.6)$ & $8.8(10.6)$ & $4(2-8)$ \\
Sever & $19(4.8)$ & $13.6(24.3)$ & $7(5-14)$ \\
Injury & & & $3(1-9)$ \\
Minor & $42(10.6)$ & $11.0(6.5)$ & $8.6(13.5)$ \\
Sever & $33(8.3)$ & &
\end{tabular}


Table 3. Risk Factors of Experiencing Any Form of Intimate Partner Violence $(N=398)$

\begin{tabular}{|c|c|c|c|c|c|c|}
\hline \multirow{2}{*}{ Characteristics } & \multirow{2}{*}{ Total Number } & \multirow{2}{*}{$\begin{array}{c}\text { No (\%) Experiencing } \\
\text { Violence }\end{array}$} & \multicolumn{2}{|c|}{ Unadjusted } & \multicolumn{2}{|c|}{ Adjusted } \\
\hline & & & OR (95\%Cl) & $P$ Value & OR $(95 \% \mathrm{Cl})$ & $P$ Value \\
\hline \multicolumn{7}{|l|}{ Woman's age (y) } \\
\hline $30+$ & 165 & 77 (47\%) & Ref. & & Ref. & \\
\hline$<30$ & 224 & $143(64 \%)$ & 2.1 (1.4 to 3.2 ) & $<0.001$ & $2.0(1.3$ to 3.3$)$ & 0.003 \\
\hline \multicolumn{7}{|l|}{ Husband's Age (y) } \\
\hline $31+$ & 270 & $150(56 \%)$ & Ref. & & & \\
\hline$<31$ & 128 & $79(62 \%)$ & 1.3 (0.8 to 2.0$)$ & 0.246 & & \\
\hline \multicolumn{7}{|c|}{ Age gap with husband $(\geq 5 y)^{*}$} \\
\hline None & 201 & $116(58 \%)$ & Ref. & & & \\
\hline$\geq 5$ years older & 195 & $111(57 \%)$ & $0.97(0.65$ to 1.4$)$ & 0.874 & & \\
\hline \multicolumn{7}{|c|}{ Length of Marriage (y) } \\
\hline$>5$ & 205 & $107(52 \%)$ & Ref. & & Ref. & \\
\hline 5 or less & 193 & $122(63 \%)$ & 1.6 (1.1 to 2.3 ) & 0.027 & 1.5 (0.94 to 2.5$)$ & 0.090 \\
\hline \multicolumn{7}{|c|}{ Woman's educational level } \\
\hline University & 119 & $63(53 \%)$ & Ref. & & Ref. & \\
\hline Diploma (12 y) & 180 & $102(57 \%)$ & $1.2(0.7$ to 1.9$)$ & 0.527 & 1.0 (0.6 to 1.7$)$ & 0.990 \\
\hline Less than diploma & 99 & $64(65 \%)$ & 1.6 (0.9 to 2.8$)$ & 0.082 & $1.4(0.7$ to 2.8$)$ & 0.330 \\
\hline \multicolumn{7}{|c|}{ Husband's educational level } \\
\hline University & 132 & 65 (49\%) & Ref. & & Ref. & \\
\hline Diploma (12 y) & 121 & $75(62 \%)$ & 1.7 (1.0 to 2.8$)$ & 0.042 & 1.5 (0.9 to 2.7 ) & 0.137 \\
\hline Less than diploma & 145 & $89(61 \%)$ & 1.6 (1.0 to 2.6$)$ & 0.043 & $1.3(0.7$ to 2.4$)$ & 0.401 \\
\hline \multicolumn{7}{|c|}{ Woman's employment } \\
\hline Housewife & 341 & $197(58 \%)$ & Ref. & & & \\
\hline Employed & 57 & $32(56 \%)$ & $0.9(0.5$ to 1.6$)$ & 0.818 & & \\
\hline \multicolumn{7}{|c|}{ Sufficiency of family income for expenses } \\
\hline Completely & 49 & $25(51 \%)$ & Ref. & & Ref. & \\
\hline To some extent & 281 & $157(56 \%)$ & $1.2(0.7$ to 2.2$)$ & 0.529 & 1.1 (0.6 to 2.2 ) & 0.675 \\
\hline Absolutely not & 68 & $47(69 \%)$ & $2.1(1.0$ to 5.0$)$ & 0.049 & $2.0(0.9$ to 4.6$)$ & 0.105 \\
\hline \multicolumn{7}{|l|}{ Woman obesity } \\
\hline No $(\mathrm{BMI}<30.0)$ & 335 & 195 (58\%) & Ref. & & & \\
\hline Yes $(\mathrm{BMI} \geq 30.0)$ & 62 & $34(55 \%)$ & 0.9 (0.5 to 1.5$)$ & 0.622 & & \\
\hline \multicolumn{7}{|c|}{ Husband's cigarette or hookah smoking } \\
\hline No & 279 & $156(56 \%)$ & Ref. & & & \\
\hline Yes & 119 & $73(61 \%)$ & 1.3 (0.8 to 1.9$)$ & 0.316 & & \\
\hline \multicolumn{7}{|l|}{ Parity } \\
\hline Multipara & 184 & $101(54 \%)$ & Ref. & & & \\
\hline Primiparous & 214 & $128(60 \%)$ & $1.2(0.8$ to 1.8$)$ & 0.322 & & \\
\hline \multicolumn{7}{|l|}{ Planned pregnancy } \\
\hline Yes & 273 & $146(53 \%)$ & Ref. & & Ref. & \\
\hline No & 125 & $83(66 \%)$ & 1.7 (1.1 to 2.7$)$ & 0.016 & 1.6 (1.03 to 2.6$)$ & 0.038 \\
\hline \multicolumn{7}{|l|}{ Breastfeeding } \\
\hline No & 69 & $38(55 \%)$ & Ref. & & & \\
\hline Yes & 329 & 191 (58\%) & 1.1 (0.7 to 1.9 ) & 0.207 & & \\
\hline \multicolumn{7}{|l|}{ Infant sex } \\
\hline Male & 215 & $123(57 \%)$ & Ref. & & & \\
\hline Female & 183 & $106(58 \%)$ & 1.0 (0.7 to 1.5$)$ & 0.886 & & \\
\hline Husband is appoint & heir baby's gend & & & & & \\
\hline No & 305 & 167 (55\%) & Ref. & & Ref. & \\
\hline Yes & 93 & $62(67 \%)$ & 1.7 (1.0 to 2.7 ) & 0.043 & 1.9 (1.1 to 3.2 ) & 0.017 \\
\hline Meeting husband's & tations during $\mathrm{pc}$ & partum & & & & \\
\hline Fully & 167 & 85 (51\%) & Ref. & & Ref. & \\
\hline Not fully & 231 & $144(62 \%)$ & 1.6 (1.1 to 2.4$)$ & 0.023 & 1.6 (1.03 to 2.4 ) & 0.037 \\
\hline
\end{tabular}

*Two cases were omitted because the women were 5 or more years older than their husbands. OR, odds ratio, Ref: Reference. 


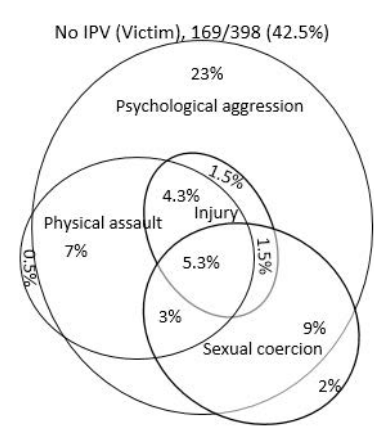

Figure 1. Prevalence of Psychological Aggression, Physical Assault, Sexual Coercion and Injury Violence by Intimate Partner During the First Year Postpartum.

which had $P<0.2$ in the bivariate analysis were entered in the multivariate regression. The results indicated that woman age of less than 30 years, unplanned pregnancy, husband disappointment about their baby's gender, and not fully meeting husband sexual expectations in the postpartum year were the predictors of postpartum IPV. In women aged less than 30 years versus those aged 30 or higher and in women with husband disappointment versus those not disappointed about their baby's gender, odds of IPV were about two times higher (OR 2.0, 95\% CI 1.3 to 3.3 ; OR $1.9,95 \%$ CI 1.1 to 3.2 , respectively) while in women with unplanned versus those with planned pregnancy and in women not able to fully meet versus those able to fully meet their husbands' sexual expectations in the postpartum year, the odds of IPV was about one and half times higher $(1.6,1.03$ to $2.6 ; 1.6,1.03$ to 2.4 ; respectively) (Table 3 ).

\section{Discussion}

In the present study, more than half of the women (58\%) reported that they had experienced one or more instance of any form of IPV (i.e., psychological, physical, sexual, and/or injury) and one-third of them reported physical assault and/or sexual coercion in the first postpartum year. The prevalence of each form of IPV were as follows: $54 \%$ psychological aggression, $21 \%$ physical assault, and 21\% sexual coercion. Woman aged less than 30, unplanned pregnancy, husband disappointment about their baby's gender, and not fully meeting sexual expectations of their husband during the postpartum year were among the predictors of higher prevalence of the overall IPV.

The findings of the present study regarding the prevalence of women's experiencing one or more instances of any form of IPV during the first postpartum year (58\%) was similar to that reported in a study conducted in Jahrom (54\%) (14). However, this prevalence was higher than that reported in most studies carried out in developed countries such as Sweden (3.3\% among women over 18 years old) (18), the United States (34\% among 15-25 yearold women) (7), and Australia (42\% among primiparous women) (19); besides, it was lower than that reported in studies conducted in some other parts of the world such as the rural areas of Bangladesh (20).

Similar to most studies conducted in Iran (14) and other countries $(1,20,21)$, the most prevalent type of IPV in the present study was psychological aggression. This prevalence (54\%) was higher than that of reported in the study conducted in Jahrom (43\%) (14), and the majority of studies in other countries $(7,21)$. However, such a prevalence was lower (84\%) than that reported in the study conducted in Bangladesh (20). Moreover, the prevalence of physical assault and sexual coercion reported in the present study was higher than that reported in most other studies $(14,21,22)$, and lower than that reported in the study conducted in Bangladesh (20).

The evaluation of IPV using the CTS2 might be one of the reasons for the high prevalence of IPV in the present study. This scale yielded the highest rates of IPV compared with other commonly used scales like the AAS or WHO IPV survey scale (23). Other possible reasons for the high prevalence of IPV were as follows: women's lack of familiarity with their own legal rights and consequently not making any attempt to prevent IPV committed by their husbands, trying to preserve the family's unity under any circumstances, fear of divorce, justifying the acceptability of IPV committed by their husbands, and the culture of patriarchy and keeping secrets in families.

It is reported that the risk of psychological aggression and sexual coercion might increase during the postpartum period for a number of reasons such as increased stress due to the child's entry into the family, nocturnal sleeping problems (insomnia), and decreased sex drive in women (24). However, comparing the results of the present study with those of a recent study conducted on 20-29 year-old nulliparous pregnant women in the same study setting with the same scale (12) no obvious difference was observed between the prevalence of IPV during pregnancy and the first postpartum year in the region. In the abovementioned study, the prevalence of experiencing any IPV (i.e., psychological, physical, sexual, and/or injury) was $62 \%$ while the prevalence of experiencing physical assault and/or sexual coercion was $37 \%$. In addition, the prevalence of experiencing psychological aggression was $56 \%$ (minor $49 \%$, severe $37 \%$ ) as compared to the prevalence of experiencing physical assault which was $26 \%$ (minor $22 \%$, severe $13 \%$ ). Moreover, the prevalence of experiencing sexual coercion was found to be $21 \%$ (minor $18 \%$, severe $6 \%$ ) while the prevalence of experiencing injury was $11 \%$ (minor $8 \%$, severe $9 \%$ ).

In terms of women's age less than 30 years as one of the predictors of postpartum IPV, the results of the present study are consistent with the results of a study by Radestad et al on postpartum women in Sweden (25) and a study by the WHO on the general population of women of reproductive age in 10 countries (9). In the study by the WHO, women's young age had a significantly strong correlation with increased IPV in 12 out of 15 investigated regions. This could be due to the young couples' lack 
of proper knowledge of each other, lack of enough knowledge about the purpose of marriage and spousal responsibilities, and also lack of enough maturity to solve the problems.

Unplanned pregnancy was another predictor of IPV, which is consistent with the results of a study by Charles and Perreira in the United States (26). However, the results of these studies could not prove that unplanned pregnancy resulted in increased postpartum IPV because this correlation might be due to the strong relationship between the prevalence of IPV before and after the pregnancy (27) and also due to the positive correlation between pre-pregnancy IPV and unintended pregnancy. Studies by Azevedo et al in Brazil (28) and Kamal in Bangladesh (29) also showed that there was a positive correlation between pre-pregnancy IPV and unintended pregnancy.

Besides, women's inability to fully meet their husband's sexual needs was another predictor of IPV, which is in conformity with the results of a study on a large number of the general population in the United States indicating the increased risk for IPV due to sexual dissatisfaction (30).

Age difference between husbands and wives (men 5 or more years older than women) in most regions studied in the multi-country study by the WHO had no correlation with the prevalence of IPV (9) which is consistent with the results of the present study. Moreover, observing no relationship between the prevalence of IPV and parity (primiparity vs. multiparity) among women is in line with some studies on postpartum women in Sweden $(18,25)$.

In some studies (8-10), low family income and low level of women's education were among the factors predicting IPV. In the present study, although bivariate analysis showed that there was a relationship between both of the above-mentioned factors and increased prevalence of IPV, multivariate analysis demonstrated that this relationship was not statistically significant.

According to most studies, drug and alcohol abuse by women or their sexual partners were among the important factors predicting the IPV (10). In the present study, however, it was not possible to determine their effect on IPV due to the few reported cases of drug and alcohol abuse (only 5 cases in the couples). It seems that the reported prevalence was lower than the actual rate owing to the illegality and taboo nature of the drug and alcohol abuse in Iran. This could be considered as one of limitations of the present study.

In Iran, people have easy access to public primary health services which provide free routine pregnancy and postpartum care. Recent health care programs have included investigation of IPV against pregnant and postpartum women in their health care formats. Therefore, given the high prevalence of IPV during pregnancy and postpartum period, health care providers are required to be fully aware of the ways of identifying the people at risk of IPV, learn how to take necessary measures to help the women victimized by IPV, and take advantage of this opportunity to identify this problem and provide preventive services. A trial conducted by Kiely et al (31) showed that holding individually tailored counseling sessions as a relatively short intervention during pregnancy could significantly help prevent the recurrence of IPV during other periods of women's lives.

It is recommended that prospective longitudinal studies on IPV be carried out including the women who intend to get pregnant and following them during pregnancy and postpartum period. Such studies can help better identify the changes in the prevalence of each form of IPV over these periods and their risk factors. Moreover, given the high prevalence of IPV and its negative effect on women's and children's health, interventional studies are urgently needed to reduce its prevalence and lor chronicity because the results of the limited studies conducted in other countries might not be generalizable to this specific region due to the effect of cultural and social factors on effectiveness of the interventions.

\section{Conclusions}

The IPV during postpartum is very common. Therefore, it is recommended to implement IPV screening programs and effective strategies for IPV prevention in the health care settings for newly delivered women with an emphasis on the high risk for women.

\section{Ethical Issues}

This project was approved by the Ethical Committee of Tabriz University of Medical Sciences (under the code of ethics TBZMED.REC.1394.633).

\section{Conflict of Interests}

The authors declare that there is no conflict of interests.

\section{Financial Support}

Financial support was provided by the Deputy of Research of Tabriz University of Medical Sciences.

\section{Acknowledgements}

The authors hereby would like to extend out their sincerest gratitude and appreciation to all the personnel and health care providers at the health centers/posts in Tabriz for their collaboration and also all the participants for filling out the questionnaires carefully and patiently.

\section{References}

1. WHO. Violence against women: Intimate partner and sexual violence against women 2016 [cited 4/8/2017]. http://www.who.int/mediacentre/factsheets/fs239/en/. Accessed April 8, 2017.

2. Hajnasiri H, Ghanei Gheshlagh R, Sayehmiri K, Moafi F, Farajzadeh M. Domestic Violence Among Iranian Women: A Systematic Review and Meta-Analysis. Iran Red Crescent Med J. 2016;18(6):e34971. doi:10.5812/ 
$\operatorname{ircmj.34971}$

3. Martin SL, Arcara J, Pollock MD. Violence during pregnancy and the postpartum period. Harrisburg, PA: VAWnet, a project of the National Resource Center on Domestic Violence; 2012.

4. WHO. Violence against women: the health sector responds 2013. http://www.who.int/reproductivehealth/ publications/violence/NMH_VIP_PVL_13_1/en/. Accessed August 18, 2015.

5. Coker AL, Davis KE, Arias I, et al. Physical and mental health effects of intimate partner violence for men and women. Am J Prev Med. 2002;23(4):260-268.

6. Trevillion K, Oram S, Feder G, Howard LM. Experiences of domestic violence and mental disorders: a systematic review and meta-analysis. PLoS One. 2012;7(12):e51740. doi:10.1371/journal.pone.0051740

7. Agrawal A, Ickovics J, Lewis JB, Magriples U, Kershaw TS. Postpartum intimate partner violence and health risks among young mothers in the United States: a prospective study. Matern Child Health J. 2014;18(8):1985-1992. doi:10.1007/s10995-014-1444-9

8. Moraes CL, Tavares da Silva Tde S, Reichenheim ME, Azevedo GL, Dias Oliveira AS, Braga JU. Physical violence between intimate partners during pregnancy and postpartum: a prediction model for use in primary health care facilities. Paediatr Perinat Epidemiol. 2011;25(5):478-486. doi:10.1111/j.13653016.2011.01208.x

9. Abramsky T, Watts $\mathrm{CH}$, Garcia-Moreno C, et al. What factors are associated with recent intimate partner violence? findings from the WHO multi-country study on women's health and domestic violence. BMC Public Health. 2011;11:109. doi:10.1186/1471-2458-11-109

10. Semahegn A, Mengistie B. Domestic violence against women and associated factors in Ethiopia; systematic review. Reprod Health. 2015;12:78. doi:10.1186/s12978015-0072-1

11. Bowen E, Heron J, Waylen A, Wolke D. Domestic violence risk during and after pregnancy: findings from a British longitudinal study. Bjog. 2005;112(8):10831089. doi:10.1111/j.1471-0528.2005.00653.x

12. Mohammad-Alizadeh-Charandabi S, Bahrami-Vazir E, Kamalifard M, Mirghafourvand M. Intimate partner violence during the first pregnancy: A comparison between adolescents and adults in an urban area of Iran. J Forensic Leg Med. 2016;43:53-60. doi:10.1016/j. jflm.2016.07.002

13. Hassan M, Kashanian M, Hassan M, Roohi M, Yousefi H. Maternal outcomes of intimate partner violence during pregnancy: study in Iran. Public Health. 2014;128(5):410-415. doi:10.1016/j.puhe.2013.11.007

14. Mohammadhosseini E, Sahraean L, Bahrami T. Domestic abuse before, during and after pregnancy in Jahrom, Islamic Republic of Iran. East Mediterr Health J. 2010;16(7):752-758.

15. Organization of civil registration- East Azarbaijan of civil registration. Birth statistics: 6/7; http://5.160.136.218/ en/. Accessed August 6, 2018.

16. Straus MA, Hamby SL, Boney-Mccoy S, Sugarman DB. The Revised Conflict Tactics Scales (CTS2):Development and Preliminary Psychometric Data. J Fam Issues. 1996;17(3):283-316. doi:10.1177/019251396017003001

17. Ardabily HE, Moghadam ZB, Salsali M, Ramezanzadeh F, Nedjat S. Prevalence and risk factors for domestic violence against infertile women in an Iranian setting. Int J Gynaecol Obstet. 2011;112(1):15-17. doi:10.1016/j. ijgo.2010.07.030

18. Finnbogadottir $H$, Dykes AK. Increasing prevalence and incidence of domestic violence during the pregnancy and one and a half year postpartum, as well as risk factors: -a longitudinal cohort study in Southern Sweden. BMC Pregnancy Childbirth. 2016;16(1):327. doi:10.1186/ s12884-016-1122-6.

19. Woolhouse H, Gartland D, Hegarty K, Donath S, Brown SJ. Depressive symptoms and intimate partner violence in the 12 months after childbirth: a prospective pregnancy cohort study. Bjog. 2012;119(3):315-323. doi:10.1111/j.1471-0528.2011.03219.x

20. Kabir ZN, Nasreen HE, Edhborg M. Intimate partner violence and its association with maternal depressive symptoms 6-8 months after childbirth in rural Bangladesh. Glob Health Action. 2014;7:24725. doi:10.3402/gha.v7.24725

21. Gartland D, Hemphill SA, Hegarty K, Brown SJ. Intimate partner violence during pregnancy and the first year postpartum in an Australian pregnancy cohort study. Matern Child Health J. 2011;15(5):570-578. doi:10.1007/ s10995-010-0638-Z

22. Guo SF, Wu JL, Qu CY, Yan RY. Physical and sexual abuse of women before, during, and after pregnancy. Int J Gynaecol Obstet. 2004;84(3):281-286. doi:10.1016/j. ijgo.2003.08.019

23. Desmarais SL, Reeves KA, Nicholls TL, Telford RP, Fiebert MS. Prevalence of Physical Violence in Intimate Relationships: Part 1. Rates of Male and Female Victimization. Partner Abuse. 2012;3(2):140-169. doi:10.1891/1946-6560.3.2.e1

24. Macy RJ, Martin SL, Kupper LL, Casanueva C, Guo S. Partner Violence Among Women Before, During, and After Pregnancy: Multiple Opportunities for Intervention. Womens Health Issues. 2007;17(5):290299. doi:10.1016/j.whi.2007.03.006

25. Radestad I, Rubertsson C, Ebeling M, Hildingsson I. What factors in early pregnancy indicate that the mother will be hit by her partner during the year after childbirth? A nationwide Swedish survey. Birth. 2004;31(2):84-92. doi:10.1111/j.0730-7659.2004.00285.x

26. Charles P, Perreira KM. Intimate Partner Violence During Pregnancy and 1-Year Post-Partum. J Fam Violence. 2007;22(7):609-619. doi:10.1007/s10896-0079112-0

27. Martin SL, Mackie L, Kupper LL, Buescher PA, Moracco KE. Physical abuse of women before, during, and after pregnancy. JAMA. 2001;285(12):1581-1584.

28. Azevedo AC, Araujo TV, Valongueiro S, Ludermir AB. Intimate partner violence and unintended pregnancy: prevalence and associated factors. Cad Saude Publica. 2013;29(12):2394-2404. doi:10.1590/0102311X00161111

29. Kamal SM. Domestic Violence, Unwanted Pregnancy 
and Pregnancy Termination among Urban Women of Bangladesh. J Family Reprod Health. 2013;7(1):11-22.

30. Slep AM, Foran HM, Heyman RE, Snarr JD. Unique risk and protective factors for partner aggression in a large scale air force survey. J Community Health. 2010;35(4):375-383. doi:10.1007/s10900-010-9264-3
31. Kiely M, El-Mohandes AA, El-Khorazaty MN, Blake SM, Gantz MG. An integrated intervention to reduce intimate partner violence in pregnancy: a randomized controlled trial. Obstet Gynecol. 2010;115(2 Pt 1):273283. doi:10.1097/AOG.0b013e3181cbd482

(C) 2018 The Author (s); This is an open-access article distributed under the terms of the Creative Commons Attribution License (http://creativecommons.org/licenses/by/4.0), which permits unrestricted use, distribution, and reproduction in any medium, provided the original work is properly cited. 